Artículos

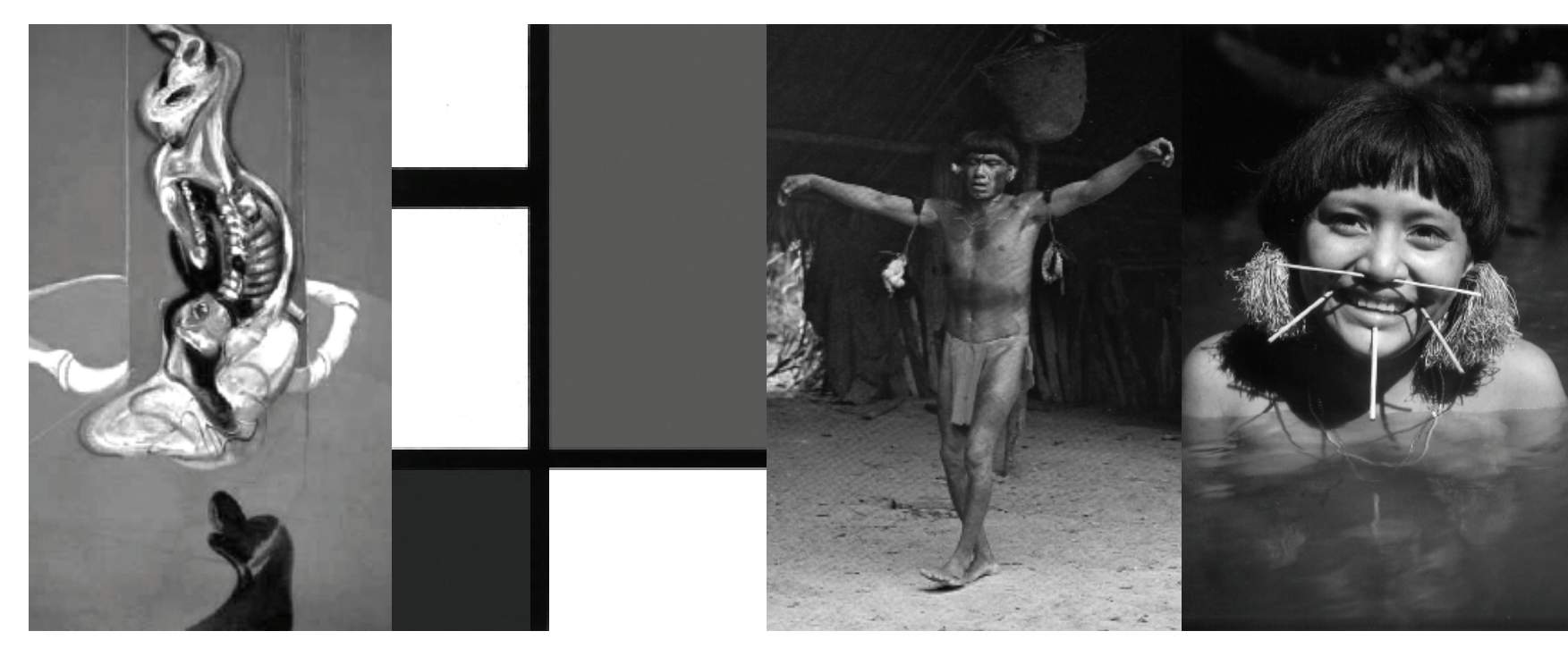




\section{El Canto Popular Religioso y la Reforma Litúrgica en España (1850-1915)}

Sacred and Secular Vocals and Liturgical Reform in Spain (1850-1915)

María Antonia Virgili Blanquet Universidad de Valladolid, España

virgili.bl@gmail.com

Resumen • El objeto de estudio es el tratamiento que recibe el Canto popular religioso y la participación del pueblo en el movimiento de reforma de la liturgia católica del siglo XIX en España. Se revisan tanto fuentes documentales como ediciones de repertorios idóneos para facilitar el canto del pueblo en latín y en lengua vernácula. Todo ello permite llegar a la consideración del movimiento reformista decimonónico como impulsor de una tendencia innovadora que el Concilio Vaticano II desarrollará: la participación activa de los fieles en la liturgia. Esta visión matiza las posturas que consideran esta reforma como un simple historicismo trasnochado y retrógrado, centrado en la recuperación del gregoriano y la polifonía religiosa como modelos de la nueva composición religiosa

Palabras clave: Canto popular religioso, canto del pueblo en la liturgia, liturgia católica, congreso de música religiosa, música religiosa del siglo XIX.

Abstract • Abstract The study focuses on the way in which Sacred and Secular vocal music and people's participation was treated by the Reform Movement of Catholic Liturgy in Spain during the XIXth century. The essay analyses both documentary sources and repertoire editions which aim was to facilitate congregation's singing in Latin as well as in vernacular language. All this allows us to conclude that XIXth Reform stimulated an innovative trend developed by Vatican Council II: the active participation of people in the Liturgy. These results show a different approach in contrast with current opinions that consider the Liturgical Reform Movement as a simple old-fashioned and retrograde historicism just focused on Gregorian and religious polyphony as historical models for new sacred musical compositions.

Keywords: Sacred and Secular Vocal, People's Vocal in Liturgy, Catholic Liturgy, Sacred Music Congress, Sacred Music in the XIXth Century. 
Son dos los ámbitos que me propongo relacionar en este trabajo: de una parte el mundo del canto popular religioso, que hunde sus raíces en los orígenes de la humanidad si abrimos al máximo el concepto de "religioso" y de otra, un espacio absolutamente acotado, como es la música en la liturgia católica de la segunda mitad del siglo XIX y comienzos del XX.

\section{ANTECEDENTES:}

En los albores del cristianismo, el canto popular religioso está presente de forma natura en los cultos que se desarrollan al cesar las persecuciones de los primeros siglos. Sin embargo, el período medieval y la evolución del concepto de liturgia en el culto cristiano, van bargo, el período medieval y la evolución del concepto de liturgia en el culto cristiano, van
relegando la participación del pueblo a un segundo plano, llegando incluso a desaparecer como elemento activo de la celebración (Gelineau, 1967: 244). Cambios estéticos, como los que conlleva el arranque y desarrollo de la polifonía, exigen grupos de cantores especializados a los que el pueblo simplemente escucha. El canto popular alcanzará protagonismo sólo en los actos paralitúrgicos y en géneros sencillos de lengua vernácula. Hay que hacer, sin embargo, la salvedad de que no es lo mismo la liturgia solemne, desarrollada en una catedral o en un centro religioso importante, que la liturgia de una pequeña parroquia, sin medios propios para mantener un grupo especializado de cantores, salvedad que es válida para este momento histórico, pero de igual forma para los posteriores.

En pleno periodo de esplendor de la polifonía del siglo XVI, hay sin embargo otros ámbitos en los que el canto popular está muy presente, como es la enseñanza del catecismo y la formación cristiana. Asimismo, la cristiandad se expande por el nuevo continente americano en una labor misional que exigirá nuevos medios catequéticos, en los que la música y el canto tendrán una importancia de primer orden. Estos procedimientos ya se habían utilizado en zonas geográficas en las que apenas existían sacerdotes y la formación del pueblo era muy escasa. Alfonso de Vicente, en su interesante estudio sobre este tema, examina diversas fuentes musicales relacionadas con la utilización del canto este tema, examina diversas fuentes musicales relacionadas con la utilización del canto
monódico en castellano por parte de los movimientos reformistas fieles al catolicismo romano. Dichas fuentes van desde los intentos catequizadores y alfabetizadores, hasta el espectáculo de las procesiones masivas o el desarrollo de devociones piadosas (De Vicente, 1967).

Este autor recuerda que, desde los primeros catecismos, cuyas referencias han llegado hasta nosotros, el canto se incorpora como medio insuperable para que los niños no sólo lo aprendan, sino que lo canten en sus casas y transmitan así la doctrina a los adultos. La mayor parte de las coplas que contienen estos libros están escritas sin música, pero hay algunas excepciones como es la Suma de toda la doctrina cristiana de Andrés Flórez (1546). De Vicente estudia asimismo algunos documentos de los Sínodos Diocesanos que (1546). De Vicente estudia asimismo algunos documentos de los Sínodos Diocesanos que
confirman, por una parte, la aceptación oficial de estas prácticas y, por otra, dan relevancia a las cofradías devocionales dirigidas a una piedad un poco más elevada que las anteriores cartillas y catecismos, pero siempre dentro de un ámbito popular. Aquí se enmarcan las cofradías consagradas al culto del rosario, de cuyas prácticas con presencia de música da fe el Processionarium secundum morem almi Ordinis Predicatorum de fray Dámaso Artufel, impreso en Madrid en 1609. También enmarcado en la devoción Mariana destaca, en este momento, el empeño de los Franciscanos por defender el dogma de la Inmaculada Concepción a través, entre otras, de manifestaciones de devoción popular.
Refiriéndonos al mundo Hispano, hay otro hecho de gran importancia con relación a la presencia de composiciones en lengua vernácula en contextos paralitúrgicos: el género villancístico. Desde mediados del siglo XVI se permite sustituir los responsorios en latín de la liturgia de las horas, en concreto de los Maitines de Navidad, por unas canciones devotas que facilitaran el entendimiento y significado de los misterios de la Encarnación y Nacimiento de Cristo (López-Calo, 2006). Este género se convertirá durante los siglos XVII y XVIII en una de las plataformas más interesantes de fusión de lo sacro y lo profano y será origen de interesantes obras del repertorio religioso hispano (Caballero, 1997). En el siglo XIX algunos autores reconocen la presencia en el género villancístico de rasgos relacionados con la música popular que, desde este género, influirán en la estética y características musicales de la música representativa de los primeros ideales nacionalistas (Villanueva, 1994: 31). expone que desde finales del siglo XVIII, después de una cierta invasión de italianismos y lirismos operísticos en la música religiosa española, se inicia una vuelta a la contención que se ve plasmada en numerosos maestros de capilla de catedrales como Burgos, Zamora, etc. (López-Calo, 2006: 594). Esta realidad, esta vuelta a un cierto purismo, pudiera tener en España un origen múltiple: por una parte las dificultades económicas y la pérdida de poder temporal de la Iglesia en los primeros años del siglo XIX, durante la ocupación francesa, así como los decretos desamortizadores, fundamentalmente el de Mendizábal en 1835 , y, por otra un cambio de gusto estético, menos ampuloso que el barroco, así como el interés por el conocimiento del pasado y de la propia historia de la música religiosa, hecho que posibilitará el que muchos compositores conozcan a los grandes polifonistas e incorporen a sus nuevas composiciones una reducción de instrumentos, un mayor esfuerzo por el entendimiento del texto y, en líneas generales, una nueva espiritualidad religiosa.

\section{LA REFORMA LITÚRGICA DE LA SEGUNDA MITAD DEL SIGLO XIX}

Al igual que en España, pero por caminos diversos de los recorridos en la península, se constata en muchos puntos geográficos del orbe católico una inquietud por elevar y dignificar la situación de la música religiosa presente en los cultos litúrgicos, pero también la usada en el contexto de la piedad popular.

Las tendencias ideológicas del Romanticismo y el desarrollo del subjetivismo, del yo como principio de reglas, deja sin duda poco espacio para un concepto trascendente del arte y aleja a los fieles del sentido comunitario de la liturgia, para poner el acento sobre las expresiones de la piedad individual (Neunheuser, 1999). No es extraño, por todo ello, que uno de los objetivos más originales e interesantes de todo este movimiento de reforma litúrgica sea el recuperar el sentido teológico de la liturgia, así como propiciar un mayor protagonismo del pueblo, buscando medios para una participación más activa y fomentando con ello el sentido de pertenencia a la comunidad celebrativa. Este movimiento ha sido reconocido por la crítica posterior como de grandes proporciones y sus pioneros hablaron ya de lengua vulgar y otros aspectos que nos sorprenden por su intuición. Como reflejo de estas inquietudes se observa un proceso de madurez en torno al concepto de liturgia, así como cierta reflexión estética que se proyectará en España en numerosos artículos y estudios sobre el tema (Virgili, 2004).

Los dos hitos más interesantes de este movimiento son, en primer lugar el Pontificado de Pío X y su Motu Proprio promulgado en 1903 (Pío X, 1903) y el Concilio Vaticano 
II con sus disposiciones sobre la liturgia contenidas en la Constitución Sacrosanctum Concilium y en otros documentos posteriores que ahondan en estas directrices (Concilio Vaticano II, 1964).

A Pío X le guió su sensibilidad y conocimiento de todo el movimiento reformista, así como su visión de la Liturgia más como valor pastoral que como valor estético y arqueológico. La promulgación de su Motu Proprio sirvió para ordenar el movimiento litúrgico, oficializarlo y, en consecuencia, infundirle nuevo vigor.

El Motu Proprio Tra le sollecitudine, de 22 de noviembre de 1903 incluye en nueve capítulos, 29 artículos y un apartado de principios generales y referencias a los géneros de música sacra, a sus relaciones con el texto litúrgico y a las formas de composición, cantores, instrumentos, disposiciones prácticas para la eficacia de la reforma: Comisiones diocesanas, creación de Scholas Cantorum y de sociedades musicales. Sus principales postulados podrían resumirse en los siguientes puntos:

La restauración del verdadero canto gregoriano, que no puede únicamente explicarse en sintonía con el gusto y la vuelta al medievalismo que propugna el espíritu romántico, sino enmarcado en la recuperación del sentido teológico de la liturgia.

La recuperación de la polifonía clásica del siglo XVI, impulsada por el movimiento cecilianista originado en Alemania.

La recuperación de los repertorios organísticos y los órganos de tubos, aspecto que quizá no adquiere tanto protagonismo como el anterior, pero que fructificará en iniciativas de gran interés.

La creación de un nuevo estilo de composición musical que tenga muy presente la funcionalidad para la que está destinada la composición y que contribuya a la dignificación de la liturgia.

En España, para algunos autores es incuestionable la labor desarrollada por el compositor Hilarión Eslava (1807-1878) como impulsor de la reforma de la música religiosa, tanto en el ámbito teórico, como en el práctico. Asimismo se constata esta preocupación en músicos y pensadores no eclesiásticos como Felipe Pedrell: las conferencias impartidas por él en el Ateneo de Madrid, en las que aborda muchas de estas preocupaciones son un claro ejemplo y, en 1895, la fundación de la Asociación Isidoriana, a iniciativa del Obispo de Madrid José María de Cos, supone ya una cierta carta de naturaleza de todo este movimiento (Labajo, 1984: 335). La Revista de esta asociación, La Música Religiosa en España ve la luz en enero de 1896 y se convertirá en altavoz de estas inquietudes reformistas. En el ámbito compositivo, la misma revista citada va dando cuenta de los cambios que se suceden en los cultos de los principales centros religiosos de la península (Virgili, 2004).

\section{EL CANTO POPULAR Y LA PARTICIPACIÓN ACTIVA DEL PUEBLO EN EL MOVI-}

\section{MIENTO REFORMISTA}

Un elemento importante de la reforma litúrgica es, como ya he indicado, la preocupación por la participación activa de los fieles y el interesante desarrollo de la piedad popular que, a su vez, genera un repertorio de cantos específicos para acompañar estas celebraciones. Considero que esta preocupación por dar voz al "pueblo" creyente en la celebración litúrgica y el fomento de una piedad individual a través de otros actos de culto no litúrgicos, no está en absoluto al margen de algunas de las corrientes ideológicas del momento: la revalorización de lo autóctono y primigenio de una nación, que se proyecta en el interés por las manifestaciones musicales de ese pueblo al considerarlas como una de las expresiones más genuinas de su propia idiosincrasia.

Por otra parte, si fijamos nuestra atención en los movimientos sociales del momento y en la aparición del asociacionismo decimonónico, observamos cómo la Iglesia no permaneció tampoco ajena a ellos y propició actividades tendentes a hacer más amable la vida de la clase obrera, así como a contribuir a su instrucción. Podríamos afirmar que todos estos movimientos sociales no quedaron al margen de la preocupación por la participación activa de los fieles y el fomento de iniciativas perfectamente inscribibles en el ámbito de la piedad popular. A finales del siglo XIX era muy frecuente que, por iniciativa de la Iglesia, se propiciara la creación de orfeones católicos vinculados con la clase obrera, enmarcados en las preocupaciones manifestadas por León XIII en su encíclica Rerum Novarum (1891). Surgen así círculos católicos de obreros, cooperativas, etc. cuyas finalidades no eran únicamente sociales, sino también religiosas e instructivas. Es este el marco propicio para la creación de orfeones de obreros que proliferan en estos años y que se suman a los ya existentes como fruto del impulso asociativo decimonónico (Nagore: 1995).

A ello debemos sumar el interés creciente por el estudio y la recopilación del folklore de cada país, íntimamente relacionado con los ideales nacionalistas del siglo XIX. La edición de numerosos Cancioneros del folklore de las regiones, en los que se incluían repertorios profanos y también religiosos y su difusión a través de la práctica de la canción armonizada, abastecieron de música muchos de los actos de piedad popular.

El movimiento coral del XIX tiene asimismo una estrecha relación con la presencia de lo popular en la reforma de la música religiosa de esta época. Como señala María Nagore y otros estudiosos del tema, hubo numerosos coros que mantuvieron una interesante relación con la Iglesia, participando en las funciones religiosas que en ella se desarrollaban. En España, los decretos desamortizadores relativos a los bienes eclesiásticos, así como la constante situación bélica de la nación, contribuyeron a la decadencia de las capillas musicales. Esta circunstancia contribuirá a que sea frecuente el recurrir a los orfeones de la ciudad, que se convertirán en colaboradores asiduos de las celebraciones litúrgicas y de las manifestaciones de piedad popular, hasta el punto que algunos autores inciden en el importantísimo papel que los coros desempeñaron en el movimiento de renovación de la música sacra (Costa,1998: 275).

Por otra parte, en el seno del propio movimiento reformista fue indispensable la creación de coros especializados en música religiosa a los que se les pudiera transmitir las inquietudes reformistas y sirvieran de instrumentos idóneos para la difusión de estos ideales: Las Scholae Cantorum de los Seminarios, las de las propias asociaciones de Santa Cecilia, Escolanías de niños, la Capilla Isidoriana de Madrid, etc. Pero ello no quiere decir que el resto de los coros y orfeones de las ciudades no incluyan en sus repertorios polifonía renacentista, canto gregoriano, canciones religiosas populares y obras de nueva creación de los compositores del momento.

Me voy a detener exclusivamente en el objeto de estudio: el canto popular y la participación del pueblo en la cronología señalada. Esta inquietud y la toma de decisiones respecto a los medios para llegar a conseguirlo, es una preocupación creciente que evoluciona desde las breves referencias que a ello hace el Motu Proprio de Pío X (1903), hasta su punto álgido con las disposiciones del Concilio Vaticano II (1965), etapa fuera ya de nuestro estudio.

En el Motu Proprio, el Papa Pío X incorpora dos breves pero interesantes recomendaciones, todavía muy limitadas, pero que servirán de punto de partida para un desarrollo 
posterior de la realidad del canto del pueblo en la liturgia, así como del canto popular religioso:

II.3.- Procúrese, especialmente, que el pueblo vuelva a adquirir la costumbre de usar del canto gregoriano, para que los fieles tomen de nuevo parte más activa en el oficio litúrgico, como solían antiguamente.

III.7.- La lengua propia de la Iglesia romana es la latina, por lo cual está prohibido que en las solemnidades litúrgicas se cante cosa alguna en lengua vulgar, y mucho más que se canten en lengua vulgar las partes variables o comunes de la misa o el oficio.

Dada la cronología en la que circunscribo este estudio, una de las fuentes de mayor interés para constatar en España el desarrollo creciente de la inquietud del canto del pueblo y de la canción popular es la documentación emanada de los Congresos de Música Sagrada, que se organizan en este período y que están directamente vinculados con el movimiento reformista. Cuando en 1907 se celebre en Valladolid el I Congreso Naciona de Música Sagrada propuesto por José María de Cos, en aquel momento Arzobispo de Valladolid, podemos afirmar que todos los elementos que integran las ideas reformistas están claramente presentes.

En relación con el tema que nos ocupa, en el congreso de Valladolid se presta atención al mismo con dos sesiones monográficas: una dedicada a "Las diversas funciones extralitúrgicas" y la segunda bajo el título "El canto popular religioso; cuál debe introducirse en los templos y cómo" (Crónica, 1907). La idea general que se plantea en la primera sesión es que deben respetarse y fomentarse tradiciones como las Novenas a la Virgen, los ejercicios dedicados a San José, las "flores" del mes de mayo, el mes del Sagrado Corazón de Jesús, os actos de piedad del mes de octubre etc. y en todos ellos podrá cantarse en lengua vulgar "con tal que hayan obtenido la aprobación correspondiente". Tras desaprobar repertorios frívolos y similares, se recomiendan las obras de sabor genuinamente popular, teniendo en cuenta que "el verdadero canto popular, el legado por nuestros mayores encierra en sí muchas veces las bellezas y formas de las más ricas melodías gregorianas” (Crónica, 1907: 18).

A esto siguen pormenores que no tienen relevancia para la cuestión general que nos ocupa. Pero sí la tiene el contenido del punto referido explícitamente al canto popular religioso: "El Congreso considerando la gran utilidad que hay en que el pueblo tome parte activa en los oficios y funciones religiosas, estima necesario el uso del canto ya sea gregoriano, ya popular religioso" (26) y el Discurso la "Música Sagrada en las Parroquias", pronunciado por Federico Olmeda (1865-1909), organista de la catedral de Burgos desde 1887, y eminente estudioso del folklore burgalés. Refiriéndose a los repertorios musicales, Olmeda expone que, para las funciones litúrgicas una parroquia tiene a su disposición la misma oferta que los grandes centros y, si le faltan elementos para poderlos interpretar, tienen "la música homófona que se precisa para todas las funciones litúrgicas". Para las funciones populares Olmeda nos brinda unas sugerentes ideas: en primer lugar expone que España no era afortunada en aquel momento y "no es música que deba ir a buscarse en el extranjero [...] debiendo ser esta música puramente española" (Olmeda, 1907: 84 85 ). No puede expresarse mejor la íntima relación entre las tendencias nacionalistas, las inquietudes de investigación del folklore de la nación, y la proyección de todo ello en la inquietudes de investigación del folklore de la nación, y la proyección de todo ello en la otras cosas, que "para estas funciones hay necesidad de una música en que pueda tomar parte activa el pueblo, con lo cual se irá disponiendo para que llegue a tomar parte también en las mismas funciones litúrgicas” (Olmeda, 1907:85). Respecto a estas necesidades de repertorio sigue Olmeda afirmando que ese repertorio existe, "vibrante, abundante y hermoso en el mismo corazón del pueblo español. Esta es la música popular sagrada, y yo la vengo oyendo desde que hace unos doce años me dedico a estudiarla en sus fuentes nativas, en el mismo pueblo" (Olmeda, 1907:85).

No acaba aquí el interés de la disertación de Olmeda sino que, más adelante, lanza un auténtico alegato nacionalista al afirmar: "Existe sí esa música que, si como sagrada está refrendada por el pueblo, es también nacional, regional, inspirada por la vivísima fe de nuestros mayores, en fin, todo digna de figurar al lado de los justamente ponderados corales alemanes e ingleses" (Olmeda, 1907:86).

Cinco años más tarde podemos comprobar cómo estas ideas se han madurado y materializado en realidades que se proyectan, entre otras, en las intervenciones de Luis Millet, destacado músico y director del Orfeó Catalá, realizadas con ocasión del III Congreso Nacional de Música Sagrada, celebrado en Barcelona en el mes de noviembre de 1912. Millet pronunció en dicho congreso una conferencia sobre La música popular religiosa en la que hace un recorrido histórico por aquellas formas litúrgico musicales que él considera han sido creadas por o para el pueblo en el transcurso de la Historia de la Iglesia, ilustrándola con ejemplos interpretados por elementos del Orfeó Catala bajo la dirección de Francisco Pujol (Millet, 1913: 175). Dos años más tarde impartirá una conferencia en julio de 1915 en el Congreso Litúrgico de Montserrat que se editará con el título El Cant del poble en les Festes de l'Esglesia, en la que pueden leerse afirmaciones que no dan cabida a la duda con relación al protagonismo otorgado al canto del pueblo en la liturgia y no tan sólo en los actos de piedad popular:

El canto es la luz de la palabra; es la expresión de los afectos sinceros y profundos; es la necesaria exteriorización de la plenitud del alma. No cantar el pueblo en la liturgia casi quiere decir distracción, incomprensión, disociación de sentimientos, o al menos, falta de la calidez amorosa que pide la expresión clamorosa de los sentimientos profundos. En la antigua liturgia, la clase humilde cantaba espontáneamente; el sentimiento vivo, la fe sincera, reclamaba el canto; en nuestra época de crisis religiosa, se ha de fomentar el canto popular en la iglesia para que la función desarrolle el órgano; se ha de orientar el sentimiento popular por medio de la participación directa en las funciones litúrgicas' (Millet, 1915: 4).

Como ya he indicado, el contexto de la primera de las intervenciones de Millet fue el III Congreso Nacional de Música Sagrada, en el que el quinto tema tratado de forma monográfica fue precisamente la "Importancia del canto del pueblo en las iglesias. Cómo lograr que los fieles canten y saquen el mayor provecho espiritual”, título suficientemente ilustrador de la importancia que en estos momentos se otorga ya al canto del pueblo y que apoya la consideración del movimiento reformista decimonónico como precedente de una tendencia innovadora en la que ahondará el Concilio Vaticano II y no únicamente como un movimiento historicista, que se limita a mirar hacia atrás al impulsar e imponer el gregoriano y la polifonía religiosa como modelos en la nueva composición religiosa.

Además de la importancia del canto del pueblo, quiero detenerme en el tema de estudio de la tercera sesion de este congreso que se formula con la interrogación "¿Pueden los compositores de música sagrada aprovecharse de las melodías populares?”. La conclusión es

La conferencia fue pronunciada en catalán y editada en el mismo idioma. La traducción que presento del texto es mía. El catalán es mi lengua materna junto al castellano. 
positiva siempre que tengan "verdadera expresión religiosa y carácter litúrgico" y pueden usarse, según la opinión del responsable de redactar esta ponencia, Enrique J. Gomá, bien presentándolas sin modificación alguna y armonizadas, o bien aprovechando el compositor los giros, ritmos y demás particularidades de la canción popular para asimilarlos y producir ideas absolutamente de su invención. Según Gomá, estas composiciones pueden usarse no sólo en los actos de piedad popular, sino también en los actos litúrgicos. El P. Gregorio Suñol añade a estas ideas que los temas populares más idóneos serán los que se parezcan a los temas gregorianos, circunstancia que da una mayor legitimidad a su empleo en la música religiosa. Sin embargo, a diferencia de lo expuesto por Gomá, Suñol defiende que estas obras deben tener "más directa cabida en las composiciones destinadas al canto del pueblo, máxime en lengua vulgar, que en las piezas propiamente litúrgicas, donde debe exigirse más estrictamente la nota de universalidad" (Suñol, 1913: 120). Dos posturas que representan, respectivamente, la moderación, la de Suñol, y el aperturismo, la de Gomá, postura que será la que definitivamente triunfa.

Como puesta en práctica de estos planteamientos, el último día del Congreso se celebró lo que se denominó Misa "popular", en la que el coro estuvo formado por más de mil voces procedentes de doce coros de Cataluña, complementados por la "Schola Puerorum", compuesta por la sección infantil del "Orfeó Catalá" y por la Escolanía de la Merced”, ésta dirigida por el maestro Lluis Millet y la gran coral por el P. Gregorio Suñol. El cronista no puede cerrar de modo más certero el éxito de la celebración y el sentir de los fieles que asistieron a ella: "esto era prácticamente lo que proclama el Congreso: la participación del pueblo fiel a la sagrada Liturgia aún en los días más solemnes”. En las conclusiones se ratifican todas estas ideas al afirmar:

El Congreso considera que es de suma importancia el canto del pueblo en las iglesias, por cuanto los fieles asisten al templo para orar, y su oración debe ser principalmente colectiva y, según palabras del reglamento de Roma, la verdadera y genuina tradición eclesiástica de canto y música sagrada es que los fieles todos se asocien por medio del canto a las funciones litúrgicas.

Los medios que propone el Congreso para lograr dicho fin son los siguientes: $1^{\circ}$. Facilitar al pueblo libros manuales de cantos; $2^{\circ}$. Que se formen núcleos de cantores en las asociaciones, parroquias, escuelas y colegios; $3^{\circ}$. Que se llame la atención a los fieles por medio de carteles y hojitas aprobadas, invitándolos a tomar parte en el canto; $4^{\circ}$. Que, como dice el Reglamento de Roma, los Párrocos inviten a los fieles a tomar parte activa en el canto y sacar del mismo todo el provecho espiritual posible; que se les instruya principalmente en el espíritu litúrgico y en el verdadero sentido de las ceremonias, con las cuales tiene estrecha relación, ya sea con pláticas, ya con un manual de piedad extracto del Misal y Breviario romano; $5^{\circ}$. Que lo que haya de cantar el pueblo sea canto gregoriano u otros cantos religiosos de sabor popular y siempre unísonos.

Todo esto tiene una proyección práctica y la actividad editorial adquiere una fuerte influencia, tanto en la difusión de estas ideas como en la de los repertorios surgidos al calor de ellas. Junto a iniciativas menos conocidas sobresalen las más culminantes, impulsadas por figuras como Felipe Pedrell o Hilarión Eslava: El Salterio Sacro-Hispano, comenzado a publicar por Pedrell en 1882 y continuado hasta comienzos del siglo, supuso, sin lugar a dudas, una de las colecciones de mayor interés e influjo en los músicos españoles de estos años.

Más relacionadas con el interés de estas páginas y mucho menos conocidas por su aparente modestia, hay otras iniciativas editoriales cuyo objetivo es precisamente facilitar la participación del pueblo en la liturgia. Si El Salterio y otras publicaciones similares daban a conocer el patrimonio de nuestra música litúrgica, polifónica y organística, en lo que atañe a los repertorios que pudiéramos llamar populares, se hace necesario un gran esfuerzo compositivo al no contar con repertorios capaces de "expresar el contenido de los ritos y de los misterios en los que se debe hacer participar a los fieles" (Gelineau, 1967: 244). Lo que se quiere pedir a estos cánticos no es la expresión de una piedad individual o únicamente una función catequética como la que hemos visto en el siglo XVI. De ellos se espera una función análoga a la del canto litúrgico con el fin de que el pueblo se asocie a los ritos. Los compositores buscan inspiración en el acervo melódico popular, siempre que concuerde con el carácter "nacional” y reúna las condiciones de su función. Todo este movimiento producirá interesantes repertorios musicales litúrgicos y paralitúrgicos y sus autores, o recopiladores, manifiestan algunos puntos en común: preocupación por difundir repertorios que permitan la participación del pueblo en la liturgia y en los actos de piedad popular, dignificar estos cantos, desarraigar determinados cantos excesivamente cercanos a lo profano y teatral, etc.

Por razones de espacio y la cronología de este trabajo, únicamente citaremos algunas de las colecciones populares más tempranas, sin ahondar de forma exhaustiva en sus contenidos ni en el impacto de las mismas. El objetivo es, en este caso, comprobar la proyección en el culto diario, litúrgico y no litúrgico, de los postulados teóricos que hemos estudiado en páginas anteriores.

Además de un número elevadísimo de ediciones sobre repertorios gregorianos, igualmente vinculados con el canto del pueblo en la liturgia pero en otra esfera de consideración, existen desde fecha temprana ediciones cuyos objetivos son difundir composiciones asequibles para el canto del pueblo. De 1862 es una edición de repertorios frecuentes, preparada por José María Hidalgo, maestro de capilla de Plasencia y, a ella sigue una publicación ya plenamente inserta en los ideales reformistas: Cantos religiosos puestos en música fácil $y$ agradable con acompañamiento de piano, armonium u órgano, propios para todas las solemnidades y épocas del año de Juan Martí y Cantó (1869). Este autor, misionero apostólico, llevaba trabajando desde hacía quince años en parroquias de zonas obreras y muy pobres de Barcelona y, de esa labor, surge la necesidad de la publicación citada. Expone en su presentación las dificultades de interpretar obras pensadas para artistas profesionales y por ello ofrece su trabajo. Prácticamente todas las composiciones que presenta son a 2 y 4 voces a capella y alguna a una voz con acompañamiento. Además de obras suyas incorpora las de compositores destacados, tanto del momento como de períodos anteriores: Bernardo Calvó y Puig, Francisco Andreví, José Elías, etc. (Martí y Cantó, 1869).

La colección de Canciones Sagradas, escogidas y editadas por J. Gimeno, tuvieron una gran difusión avalada por las numerosas ediciones que de ellas llegaron a hacerse. Aunque la que he manejado no especifica la fecha, podría afirmarse que es de muy comienzos de siglo XX. Son cantos al Sagrado Corazón, a María, Motetes al Santísimo, etc. de su misma pluma, pero también de autores extranjeros como Mozart, Paer, Miné, Cimarosa, etc. y españoles como M. Martínez, E. Escoriaza, etc. Todas ellas a solo, dos o cuatro voces (Gimeno: s.f.).

Un año antes, "Un padre de la congregación de los Sagrados Corazones" edita otra colección dirigida a los alumnos de los colegios hispano-americanos de la Congregación de los Sagrados Corazones. La novedad respecto a las anteriormente citadas es que tiene dos partes: una castellana y otra latina. La primera con cantos eucarísticos, otras para las festividades del Señor, la Virgen, los Santos y cánticos para Misiones y otras circunstancias; 
las obras en latín con Misas a una sola voz para domingos y fiestas y motetes al Corazón de Jesús, a la Virgen y a los santos (Colección de Cánticos: 1901).

En el III Congreso de Música Sagrada de Barcelona se anuncia en el Boletín Oficial del mismo, la reciente aparición del Repertorio de Cánticos Sagrados, publicado en Barcelona por José Alonso. También esta obra se edita repetidas veces. En la edición de 1924 se indica que se introducen mejoras, con un cierto cambio de gusto que lleva a descartar 65 composiciones y a incorporar 132 números nuevos. El autor lo justifica con la siguiente consideración: "hoy, que afortunadamente hanse (sic) abierto paso por doquier las saludables reformas del gran restaurador Pío X, las circunstancias aconsejan llevar más adelante en este punto el saneamiento y la perfección". La edición abarca ya todos los géneros en los que e pueblo se considera apto para poder participar y así el repertorio va desde el ordinario y los tonos comunes de la Misa, en gregoriano, a obras contemporáneas de un elenco selecto de compositores: G. Serrano, C. Candi, L. Millet, F. Pedrell, A. Insausti, A. Rodamilans, J de compositores: G. Serrano, C. Candi, L. Millet, F. Pedrell, A. Insausti, A. Rodamilans, J Nicolás, R Beobide, J. Iruarrízaga. M. Viñas, P. Guzmán, L. Perosi, Ch. Rinck, G. Ett, L. Rillé, A. Alberdi, R. Beobide, J. Busca de Sagastizábal, G. Arabaolaza, J. Lamote, J. Valdés, R. Escofet, V. Goicoechea, E. Botigliero, O. Ravanello, J. Villani, L. Villalba, etc. Sería de gran interés, pero fuera del objetivo de estas páginas, realizar un cotejo entre la primera edición y esta, analizando la estética de las obras suprimidas y los criterios de selección de las 132 nuevas (Alonso, 1912).

Es imposible detenerme en todas las ediciones que, con criterios similares, se publican en estos y posteriores años. Citaré únicamente algunas de las editadas en el arco cronológico de estas páginas. De 1913 es la Colección de cánticos religiosos para uso de las escuelas cristianas, dedicado a congregaciones y parroquias por G. Bruño. Esta obra tuvo un alcance geográfico bastante amplio, a juzgar por los lugares que se indican como depósitos para su compra: Madrid, Barcelona, París, México. El interés de esta colección es la gran preocupación que muestra por la seriedad y altura del texto y haber sido prologada por Felipe Robles, autor de un estudio sobre ortología alabado en su momento por Menéndez Pelayo. Entre los textos hay letras originales y otras adaptadas para un público infantil y continuas referencias a Pío X, así como consejos para los cantantes que reflejan su fidelidad a la reforma. Los intérpretes deben procurar, según G. Bruño: "afinación, no forzando la voz; unión perfecta de las voces, pero evitando la rigidez en el compás; piedad, dando a la voz la expresión que requieren las palabras” (Bruño, 1913).

Similares a estas obras se editan otros muchos cancioneros en la década de los veinte, como el de Patricio Beneyto, organista de la catedral de Baeza, reseñado en numerosas Revistas religiosas de España e Hispanoamérica y prologado por Casiano Rojo. La obra tiene una primera parte que es un cancionero dedicado específicamente a parroquias y una segunda con cantos catequísticos (Beneyto, 1920). Quiero citar asimismo la Colección de cantos religiosos populares de Nemesio Otaño, que, en realidad, como el mismo editor aclara "no es mas que la agrupación de 50 hojitas sueltas de otros tantos números del Repertorio Músico serie de cantos religiosos populares que bajo la dirección del P.N.Otaño, S.J. Publicó El Mensajero del Corazón de Jesús".

Para hacernos a la idea del impacto de algunas de estas iniciativas bastaría comprobar el número de ejemplares de cada edición. En 1931, por ejemplo, Mariano Plana prepara una selección de Cantos religiosos populares para uso de seminarios y parroquias y la primera edición es de 16.000 ejemplares. Una peculiaridad de esta obra, indicativa de la fuerza creciente de los regionalismos y de su relación con el canto popular religioso, es la inclusión en dicha selección de 150 cantos con texto en euskera. De igual forma se encontrarán numerosos cantos en catalán en otros cancioneros del momento.

Tras esta rápida revisión de fuentes, considero que debería matizarse la visión de la reforma litúrgica decimonónica como algo que dificultó la originalidad en la creación musical, al estar excesivamente vinculada a una estética historicista. Ahondar en el estudio de otros aspectos pueden mostrar, por el contrario, un carácter innovador como refleja la preocupación por el canto del pueblo en la liturgia y la revalorización de los elementos del folklore, puntos en común, por otra parte, con las tendencias del creciente sentimiento nacionalista/regionalista del momento y una búsqueda de las "esencias" que musicalmente pueden definir a una nación.

\section{REFERENCIAS}

Alonso, José. (1912). Repertorio de Cánticos Sagrados. Barcelona: Boileau y Bernasconi. Bruño,G.m.(1913). Colección de cánticos religiosos para uso de las escuelas cristianas, congregaciones y parroquias. Paris: Procure Générale.

Caballero Fernández-Rufete, Carmelo. (1997). "Miscent sacra profanis: música profana y teatral en los villancicos de la segunda mitad del siglo XVI". En: Música y Literatura en la Península Ibérica: 1650-1750. Valladolid: Sociedad "V Centenario del Tratado de Tordesillas" y Universidad de Valladolid.

(1901). [Un Padre de la Congregación de los Sagrados Corazones]. Colección de Cánticos Sagrados, Miranda de Ebro: Colegio de los Sagrados Corazones.

(1965). Constitución Sacrosanctum Concilium, en Acta Apostolicae Sedis 56 (1964). Madrid: 97-134. Traducción castellana: Concilio Vaticano II. Constituciones. Decretos. Declaraciones. Documentos pontificios complementarios: 148-208.

Costa, Luis. (1998). "As bases do nacionalismo musical galego no entorno da música relixiosa". En: Carlos Villanueva (ed.). Galicia fai dous mil anos. O feito diferencial galego. Santiago de Compostela: Museo do Pobo Galego.

(1907). Crónica del primer congreso nacional de música sagrada. Valladolid: Imp. Andrés Martín.

De Vicente, Alfonso. (2007). "Música, propaganda y reforma religiosa en los siglos XVI y XVII: cánticos para la "gente del vulgo" (1520-1620)”. En: Studia Aurea 1, obtenido desde: http://www.studiaaurea.com.

Gelineau, Joseph. (1967). Canto y música en el culto cristiano. Trad. M. Pilar de la Figuera. Barcelona: Juan Flors.

Gimeno, J. (s.f.) Colección de Canciones Sagradas, música escogida de varios autores modernos. Madrid: Calcografía de Lodre.

Labajo Valdés, Joaquina. (1984). José María Cos, reformista de la música sagrada en España. Revista de Musicología, VI/2: 335.

López-Calo, José. (2006). Hilarión Eslava (1807-1878), precursor del Cecilianismo en España. Revista Príncipe de Viana, 238: 577-607.

Martí y Cantó, Juan. (1869). Cantos religiosos puestos en música fácil y agradable con acompañamiento de piano, armonium $u$ órgano propios para todas las solemnidades y épocas del año, Barcelona: Imprenta y librería del heredero de D. Pablo Riera.

Millet, Luis. (1913). “La Música popular religiosa”. En: Crónica y Actas Oficiales del tercer 
Congreso Nacional de Música Sagrada. Barcelona: Talleres Tipográficos La Hormiga de Oro.

-. (1915). El Cant del poble en les Festes de l'Esglesia. Barcelona: Tipografía de L'Avenç.

Nagore, María. (1995). "La Música coral en España en el siglo XIX”. En Emilio Casares y Celsa Alonso (ed.) La Música española en el siglo XIX. Oviedo: Servicio de Publicaciones Universidad de Oviedo.

Neunheuser, Burkhard. (1999). Storia della liturgia attraverso le epoche culturali. Roma: CLV-Edizioni Liturgiche.

Olmeda, Federico. (1907). "La Música sagrada en las parroquias”. En Crónica del Primer Congreso Nacional de Música Sagrada. Valladolid: Imp. Andrés Martín.

Pio X. (1903) Motu proprio Inter pastorales officii (Tra le sollecitudin), de 22-XI-1903, en Acta Apostolicae Sedis, 36 (1903-1904): 329-339. Traducción castellana: A.Pardo, Documentación litúrgica. Nuevo Enchiridion. De san Pío X a Benedicto XVI. Burgos 2006, nn. 1-18.

Suñol. Gregorio María. (1913). "Memoria sobre el tema tercero de la sección segunda: canto popular". En Crónica y Actas Oficiales del tercer Congreso Nacional de Música Sagrada. Barcelona: Talleres Tipográficos La Hormiga de Oro.

Villanueva, Carlos. (1994). Los Villancicos gallegos. A Coruña: Fundación Barrié de la Maza.

Virgili Blanquet, María Antonia. (2004). "Antecedentes y contexto ideológico de la recepción del Motu Proprio en España”. Revista de Musicología, 1: 23-43.

Recepción: miércoles 9 de septiembre de 2009 Aceptación: martes 26 de enero de 2010 